\title{
The effects of prosthetic ankle stiffness on stability of gait in people with
} transtibial amputation

\author{
Matthew J. Major, PhD; ${ }^{1-2 *}$ Martin Twiste, PhD; ${ }^{2-3}$ Laurence P. J. Kenney, PhD; ${ }^{2}$ David Howard, PhD ${ }^{2}$ \\ ${ }^{1}$ Northwestern University Prosthetics-Orthotics Center, Chicago, IL; and Jesse Brown Department of Veterans Affairs \\ Medical Center, Chicago, IL; ${ }^{2}$ Centre for Health Sciences Research, University of Salford, Salford, UK; ${ }^{3}$ United \\ National Institute for Prosthetics \& Orthotics Development, University of Salford, Salford, UK
}

\begin{abstract}
The ability to control balance during walking is a critical precondition for minimizing fall risk, but this ability is compromised in persons with lower-limb absence because of reduced sensory feedback mechanisms and inability to actively modulate prosthesis mechanical function. Consequently, these individuals are at increased fall risk compared with nondisabled individuals. A number of gait parameters, including symmetry and temporal variability in step/stride characteristics, have been used as estimates of gait stability and fall risk. This study investigated the effect of prosthetic ankle rotational stiffness on gait parameters related to walking stability of transtibial prosthesis users. Five men walked with an experimental prosthesis that allowed for independent modulation of plantar flexion and dorsiflexion stiffness. Two levels of plantar flexion and dorsiflexion stiffness were tested during level, uphill, and downhill walking. The results demonstrate that low plantar flexion stiffness reduced time to foot-flat, which was associated with increased perceived stability, while low dorsiflexion stiffness demonstrated trends in temporal-spatial parameters that are associated with improved gait stability (reduced variability and asymmetry). Prosthesis design and prescription for low rotational stiffness may enhance gait safety for transtibial prosthesis users at risk of unsteadiness and falls.
\end{abstract}

Key words: amputation, below-knee, biomechanics, foot, gait, prosthesis, stability, stiffness, symmetry, variability.

\section{INTRODUCTION}

Individuals with lower-limb amputation are at increased risk of falling compared with age-matched nondisabled controls and have reduced confidence in their balance, both contributing to their restricted mobility and reduced participation in daily activity [1-3]. Their ability to control balance during walking is a critical precondition for minimizing the risk of falls and has a direct relationship with walking performance [4-5]. Individuals with lower-limb amputation are restricted in their ability to produce rapid gait adjustments to maintain gait stability, probably as a result of poor somatosensory feedback from the prosthesis and residuum as well as reduced lower-limb muscle strength [4,6-9]. Further, they are

\footnotetext{
Abbreviations: $\mathrm{CFAM}=$ custom foot-ankle mechanism, $\mathrm{CV}=$ coefficient of variation, DOWN = self-selected walking speed on a 5 percent downhill slope, $\mathrm{FWS}=$ fast walking speed, $\mathrm{HI}=$ high stiffness, HIHI = high dorsiflexion and plantar flexion stiffness, HILO = high dorsiflexion and low plantar flexion stiffness, $\mathrm{LO}=$ low stiffness, $\mathrm{LOHI}=$ low dorsiflexion and high plantar flexion stiffness, LOLO $=$ low dorsiflexion and plantar flexion stiffness, SSWS = self-selected walking speed on the level, UP $=$ self-selected walking speed on a 5 percent uphill slope.

*Address all correspondence to Matthew J. Major, PhD; 680 N Lake Shore Dr, Ste 1100, Chicago, IL 60611; 312503-5731. Email: matthew-major@northwestern.edu http://dx.doi.org/10.1682/JRRD.2015.08.0148
} 
unable to actively modulate the mechanical function of passive prostheses [10-13].

In this context, gait stability is typically assessed using proxy measures, such as degree of gait variability because of its relationship with falls as valid across various patient groups and locomotor impairments [14-15]. The variability of temporal-spatial gait parameters, such as coefficient of variation (CV) of step time, has often been used as an indicator of gait stability as a result of its relationship with lower-limb motor impairment and fall risk [14,16-19]. For example, individuals with neurological impairments that can cause gait unsteadiness (e.g., Parkinson disease and Huntington disease) display increased stride and swing time variability compared with nondisabled controls [20]. Indeed, swing time variability has been used as a proxy measure of gait stability in a study involving subjects with chronic hemiparesis [18]. Similarly, in one study individuals with transtibial amputation who had experienced a fall within a 12 mo retrospective period exhibited greater prosthetic limb swing time variability than nonfallers [19]. Previous work has also suggested that changes in the means of the spatial parameters can reflect actual and perceived instability, such as the relationship between increased stride time and falls as well as step width and fear of falling in the elderly [16-17,21]. Generally, individuals with lower-limb amputation also walk with a wider step width, which may be a strategy to emphasize passive mechanisms (e.g., widening the medial-lateral base of support) for increasing stability $[10,13,22]$.

Furthermore, the gait of individuals with lower-limb amputation is less symmetric, most prominently reflected by reduced single-support time on the prosthetic limb [2326]. This asymmetry may reflect a desire to shorten weight-bearing on the prosthesis [24,27], perhaps to protect the residuum [28-29], and/or to compensate for the mechanical limitations of the prosthesis (e.g., lack of late stance plantar flexion) [23,27-30]. Asymmetry during gait appears to be associated with increased incidence of falls. For example, right-left swing time asymmetry of elderly idiopathic fallers (two or more falls in the previous year) was three times greater than elderly controls and was similar to patients with Parkinson disease [31]. Swing time symmetry has also been used to indicate improvements in gait stability resulting from orthotic interventions for chronic hemiparesis [18]. Similarly, gait asymmetry and reliance on the sound limb in unilateral lower-limb prosthesis users has been used as an indicator of disability and associated with perceived instability in gait [24-26].
To aid walking stability, it has been suggested that passive transtibial prostheses should quickly achieve foot-flat and have nondisabled, nonamputee roll-over kinematics and hence tibial progression, both of which are directly affected by prosthetic ankle stiffness [32-35]. Previous research on systematic variations in prosthesis stiffness has suggested that low dorsiflexion stiffness facilitates kinematics more similar to the gait of nondisbled people without amputation and that reductions in foot stiffness encourage gait adaptations reflective of an enhanced ability to control upright posture [36-37]. Additionally, the gait of individuals with bilateral transtibial amputation displays a reduction in step width with increased prosthetic ankle range of motion, suggesting improved balance confidence $[13,38]$.

Therefore, the purpose of this preliminary study was to systematically observe the effects of ankle rotational stiffness on the temporal-spatial gait parameters of individuals with transtibial amputation and their self-perceived stability during level, uphill, and downhill walking at different speeds using an experimental prosthesis with adjustable mechanical properties. Walking on slopes and at a fast speed was included to more closely reflect the reality of community walking and enable generalization of the results beyond level walking at self-selected speed [39]. The use of an experimental prosthesis with adjustable mechanical properties is a novel and convenient method for performing in vivo studies that aim to establish the effect of isolated properties on user performance, thereby aiding understanding of the fundamental relationship between prosthesis mechanical function and prosthetic gait quality $[36,40]$. We hypothesized that low plantar flexion stiffness would reduce the time to foot-flat [32-33,35], and that time to foot-flat would be inversely related to perceived stability $[10,13,22]$. We also hypothesized that low dorsiflexion stiffness that facilitates walking kinematics more similar to the gait of nondisabled people without amputation, particularly tibial progression, would improve gait stability [32,34-36].

\section{METHODS}

\section{Custom Foot-Ankle Mechanism}

Changing prosthetic components and alignment alters prosthesis mechanical properties in a complex and interactive manner [41]. Consequently, this study avoided the use of commercial prostheses to systematically test a range of ankle stiffness without simultaneously altering 


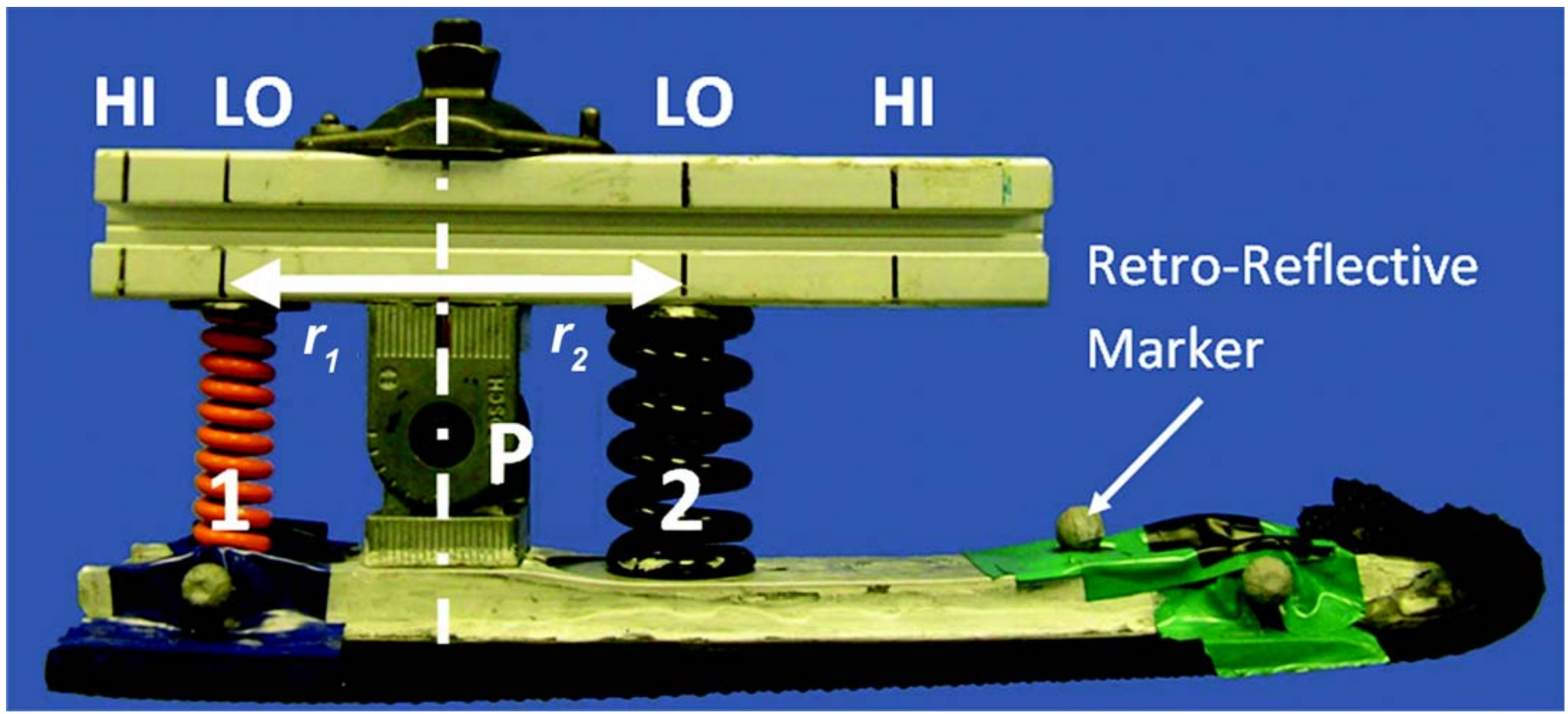

Figure 1.

Custom foot-ankle mechanism with retro-reflective markers used for motion capture. Plantar flexion and dorsiflexion rotational stiffnesses are determined by translating two linear springs ( 1 and 2 , respectively) along an upper track to vary their distances ( $r_{1}$ and $\left.r_{2}\right)$ from the central (ankle) joint (P). Plantar flexion stiffness $\left(K_{\text {rot }, 1}\right)$ and dorsiflexion stiffness $\left(K_{\text {rot }, 2}\right)$ are described by $K_{r o t, i}=K_{\text {lin }, i} \times r_{i}^{2}$ for $\mathrm{i}=1$ and 2 , where $K_{\operatorname{lin}, i}$ is the linear stiffness of the respective springs. The vertical black lines on the upper rail mark spring positions for high and low plantar flexion (left of the vertical dashed line) and dorsiflexion (right of the vertical dashed line) stiffness. The lower track can be separated from the upper profile at the central joint to allow for adjustment of the springs without altering alignment. LO = low stiffness, $\mathrm{HI}=$ high stiffness. Figure 1 was previously printed in Major et al. [36] and is reprinted with permission.

other properties. The custom foot-ankle mechanism (CFAM) designed and fabricated for this study (Figure 1) allowed independent modulation of the plantar flexion and dorsiflexion rotational stiffnesses of a single-axis ankle joint (i.e., the change in resisting torque per unit angular rotation) without simultaneously changing other mechanical properties or requiring modification of prosthesis alignment. The design and characterization of the CFAM is described in detail by Major et al. [36,42]. Importantly, the CFAM was designed to be used without shoes to reduce the confounding influence of different shoe material properties and maintain complete control of the prosthesis properties, but treading was attached to the plantar surface to increase friction between the prosthesis and the ground (i.e., treadmill). Relevant characteristics of the CFAM include mass of $1.1 \mathrm{~kg}$, forefoot length (foot lever distance from ankle joint to toe end) of $213 \mathrm{~mm}$, rearfoot length (foot lever distance from ankle joint to heel end) of $70 \mathrm{~mm}$, and ankle joint height (longitudinal distance between the ankle joint and floor in neutral position) of $49 \mathrm{~mm}$. Although CFAM deformation during weight bearing is primarily dependent on rotation of the articulating joint and not on compressible continuous structures such as leaf springs, the prosthetic foot deforms under load as would occur with nonarticulated devices.

The CFAM was used to independently test changes between two plantar flexion and two dorsiflexion rotational stiffnesses that reflect the high (HI) and low (LO) stiffness bounds seen in commercially available prosthetic feet [36]: LO plantar flexion $=94.20 \mathrm{~N}-\mathrm{m} / \mathrm{rad}$, LO dorsiflexion $=394.3 \mathrm{~N}-\mathrm{m} / \mathrm{rad}$, HI plantar flexion $=$ $202.8 \mathrm{~N}-\mathrm{m} / \mathrm{rad}$, and HI dorsiflexion $=1,395.7 \mathrm{~N}-\mathrm{m} / \mathrm{rad}$. To address the possibility of interaction effects, stiffness combinations were tested using four CFAM setups:

- $\mathrm{LOLO}=$ low dorsiflexion and low plantar flexion stiffness - LOHI = low dorsiflexion and high plantar flexion stiffness - HILO = high dorsiflexion and low plantar flexion stiffness - HIHI = high dorsiflexion and high plantar flexion stiffness. 


\section{Participants}

Participants were included if they possessed an amputation resulting from trauma, were free from neurological or other musculoskeletal pathologies, had at least $1 \mathrm{yr}$ of prosthesis use, and were able to walk continuously for 10 min without an aid other than the prosthesis. For the purpose of this study, a new experimental prosthesis was fabricated for each participant, using a total surface bearing Icecast socket and an Iceross liner (Össur Hf.; Reykjavík, Iceland) with shuttle-lock pin suspension, as well as the CFAM attached to the socket via a rigid pylon.

\section{Data Collection}

Participants visited the research laboratory on three occasions. The first visit involved obtaining informed consent, casting the residuum for fabrication of the new socket, collecting descriptive measurements, walking for 10 min continuously on a treadmill (Vision Fitness; Cottage Grove, Wisconsin) at a comfortable speed to familiarize the participants with treadmill walking without using handrails, recording their self-selected walking speed, and ensuring they were capable of walking for 10 min with a consistent gait.

During the second and third visits, the participants were fitted with their experimental prosthesis. Standard clinical alignment was performed with the CFAM in the most compliant condition (LOLO), involving initial bench alignment followed by common clinical static and dynamic alignment techniques to eliminate bilateral limb-length discrepancy, ensure patient comfort, and produce a smooth gait with minimal compensations as verified by prosthetist observation and participant feedback [43]. The participants then walked around the room for at least $10 \mathrm{~min}$ to become accustomed to the experimental prosthesis. Following this, retro reflective markers were attached to the sound foot and prosthesis for optical motion capture at $100 \mathrm{~Hz}$ sampling frequency (Vicon Motion Systems Ltd; Oxford, England). On the sound foot, markers were attached on the shoe at locations of the navicular, first and fifth tarsal-metatarsal joints, and posteriorly to represent the heel. On the prosthesis, markers were attached on the forefoot and the heel (Figure 1), three on the lateral aspect of the socket, and two on the ankle pivot (medial and lateral) to define the joint center as the segment's end point. In conjunction with the foot markers, markers on the socket were used to define the shank segment for estimation of prosthetic ankle joint kinematics. The foot markers were also used to define the foot segment for estimation of gait events with sufficient redundancy to account for possible marker occlusion.

Following marker attachment, each of the four CFAM setups was tested during four conditions:

- SSWS = self-selected walking speed on the level

- FWS = fast walking speed (150\% of SSWS)

- UP $=$ self-selected walking speed on a 5 percent uphill slope

- DOWN = self-selected walking speed on a 5 percent downhill slope.

SSWS was determined by identifying the speed that the participant considered "comfortable and safe" while walking on the treadmill with his own prosthesis. Participants were subsequently allowed to select a new walking speed if they felt this was necessary after donning the experimental prosthesis, but this speed was then held constant throughout all testing conditions.

For each CFAM condition, the alignment was held constant as determined by the LOLO setting. Although contradictory to standard clinical practice, this deliberate choice of holding alignment constant allowed for observation of changes in gait stability solely as a result of independent adjustments in prosthesis mechanical properties and separate from changes in alignment, which would also indirectly and jointly modify plantar flexion and dorsiflexion mechanical function.

Participants started each treadmill walking trial by holding onto the handrail while the speed was increased to self-selected speed. The participants released the handrails when comfortable and walked for $5 \mathrm{~min}$, of which only the final $30 \mathrm{~s}$ was used for data analysis in accordance with normal treadmill walking in order for step parameter variability to settle [44]. The $30 \mathrm{~s}$ data collection period allowed for 12 total steps to be recorded. A previous study suggested that this is a sufficient number of steps to estimate temporal-spatial variability of gait that possesses both sufficient test-retest reliability and concurrent validity with measures of health, functional status, and physical activity [45].

It was necessary to keep the total testing time to a minimum after acclimatization at SSWS. Therefore, for each CFAM setup, first SSWS and then FWS (i.e., on the level) were tested. After that, the two graded walking conditions were tested in randomized order. The order of CFAM setup testing was also randomized. Two CFAM setups were tested during the second and third visits, with as much seated rest between CFAM setups as requested 
to avoid fatigue. All participants opted for seated rest, and the minimum rest time was $10 \mathrm{~min}$.

Participants' perceived stability was recorded on an ordinal scale from 1 to 10 . Using language adopted from the Activities-specific Balance Confidence Scale [46], which is a common validated measure for use with lower-limb prosthesis users [2,47-48], participants were asked to rate "How steady and confident do you feel?" from 1 ("very unsteady and at immediate risk of falling") to 10 ("completely stable and confident").

\section{Data Analysis}

Motion data were filtered using a low-pass Butterworth filter with a $6 \mathrm{~Hz}$ cutoff. Initial contact and toe-off of both feet were estimated from kinematic data using custom software in MATLAB (MathWorks; Natick, Massachusetts), which also enabled calculation of bilateral step width, bilateral step time, and prosthetic limb swing time [49]. CFAM ankle joint motion was derived using Visual 3D motion analysis software (C-Motion Inc; Germantown, Maryland) and the Calibration Anatomical Systems Technique [50]. The mean and CV, defined as the within-participant standard deviation divided by the mean, of prosthetic limb swing time and step time for each condition, were calculated over 12 consecutive steps. A simple measure of temporal symmetry was used: the ratio of mean sound limb swing time divided by mean prosthetic limb swing time. Step width and prosthetic limb time to foot-flat (i.e., maximum plantar flexion) were normalized by participant body height and stance time, respectively.

\section{Statistical Analysis}

A linear mixed-model analysis was conducted to evaluate the main and interaction effects of walking condition (SSWS, FWS, UP, and DOWN), dorsiflexion stiffness (LO and HI), and plantar flexion stiffness (LO and HI) on each dependent variable (time to foot-flat, prosthetic limb swing time $\mathrm{CV}$, step time $\mathrm{CV}$, step width, and symmetry ratio). The linear mixed model assigned walking and stiffness conditions as repeated fixed effects, subject as a random effect, and use of the Bonferroni correction to account for type I error resulting from multiple post hoc comparisons. This analysis allowed for observation of prosthesis stiffness main effect across all walking conditions that reflect general community ambulation. Additionally, observation of main effect differences in walking condition across all stiffness conditions provides insight into relative challenges in stability associated with different walking scenarios. The strength of monotonic association between time to foot-flat and perceived level of stability was estimated by Spearman rho using data across all walking and prosthesis conditions. All tests were performed using SPSS version 20 (IBM Corporation; Armonk, New York), and the critical alpha was set at 0.05.

\section{RESULTS}

Eight individuals were recruited. Two participants withdrew as a result of feeling uncomfortable with treadmill walking and one because of the time commitment. The remaining five male participants had all experienced amputation as a result of trauma for at least $2 \mathrm{yr}$ prior to the study and were considered unlimited community ambulators. The participants' prescribed prosthetic feet were a nondynamic foot (i.e., solid ankle cushion heel; $n=1)$ and various energy storage-and-return feet $(n=4)$. Detailed participant characteristics and averages can be found in Table 1.

One participant grasped the handrails with the HIHI CFAM setup in all walking conditions, and therefore these data have been excluded from the analysis for only that CFAM setup. For FWS, the same participant felt comfortable increasing his walking speed to only 133 percent of SSWS as opposed to 150 percent for all other participants, but these data were included because this condition represented a considerable increase in walking speed above his customary speed.

The effects of the prosthesis conditions tested in this study on maximum plantar flexion and dorsiflexion have been presented in a previous publication and confirm that LO is associated with a significant increase in ankle range of motion [36].

Table 2 displays the statistical results for the main effects, and Table 3 displays results for multiple comparison tests for those main effects that were statistically significant, respectively. The main effect differences for walking scenario, dorsiflexion stiffness, and plantar flexion stiffness presented in these tables are values resulting from collapsing across the remaining independent variables in accordance with the statistical methods. No interaction effects were statistically significant $(p \geq 0.08)$, so these results are not presented in detail. Figures 2-6 display the average values of the dependent variables at each walking and prosthesis condition, graphically illustrating the main effect trends. The values for dorsiflexion 
JRRD, Volume 53, Number 6, 2016

Table 1.

Participant characteristics.

\begin{tabular}{|c|c|c|c|c|c|c|c|}
\hline Participant & $\begin{array}{l}\text { Age } \\
\text { (yr) }\end{array}$ & $\begin{array}{c}\text { Mass } \\
\text { (kg) }\end{array}$ & $\begin{array}{l}\text { Height } \\
\text { (m) }\end{array}$ & $\begin{array}{l}\text { Residuum Length } \\
\text { (mm) }\end{array}$ & $\begin{array}{c}\text { Time Since } \\
\text { Amputation } \\
\text { (yr) }\end{array}$ & $\begin{array}{l}\text { Prosthetic } \\
\text { Side }\end{array}$ & $\begin{array}{c}\text { Prescribed Prosthetic } \\
\text { Foot }\end{array}$ \\
\hline$\overline{1}$ & 56 & 93 & 1.84 & 125 & 46 & Left & Ottobock SACH* \\
\hline 3 & 56 & 91 & 1.85 & 170 & 53 & Right & Hanger Quantum \\
\hline 4 & 39 & 96 & 1.84 & 130 & 6 & Left & Össur Ceterus ${ }^{\S}$ \\
\hline \multicolumn{8}{|c|}{ 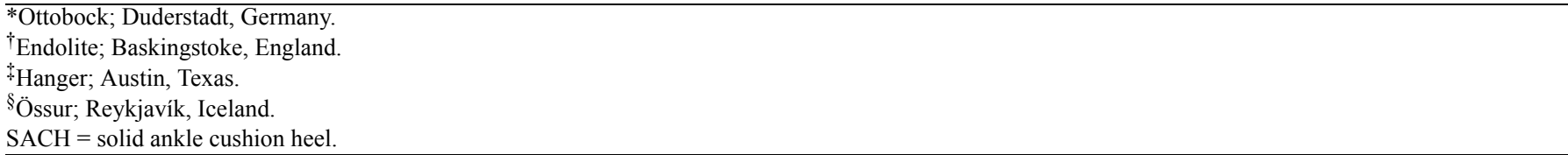 } \\
\hline
\end{tabular}

Table 2.

Main effect statistical results explaining the influence of walking and prosthesis stiffness conditions.

\begin{tabular}{|c|c|c|c|c|c|c|}
\hline \multirow{2}{*}{ Parameter } & \multicolumn{2}{|c|}{ Walking Scenario Effect } & \multicolumn{2}{|c|}{ Dorsiflexion Stiffness Effect } & \multicolumn{2}{|c|}{ Plantar Flexion Stiffness Effect } \\
\hline & F-Value & p-Value & F-Value & $p$-Value & F-Value & $p$-Value \\
\hline Time to Foot-Flat & 11.471 & 0.001 & 2.944 & 0.09 & 24.524 & 0.001 \\
\hline $\begin{array}{l}\text { Prosthetic Limb Swing } \\
\text { Time CV }\end{array}$ & 4.283 & 0.01 & 7.370 & 0.009 & 3.356 & 0.08 \\
\hline Step Time CV & 5.328 & 0.006 & 12.738 & 0.001 & 0.526 & 0.48 \\
\hline Step Width & 3.166 & 0.04 & 9.855 & 0.003 & 0.723 & 0.41 \\
\hline Symmetry Ratio & 4.730 & 0.009 & 15.297 & 0.001 & 2.685 & 0.12 \\
\hline
\end{tabular}

Table 3.

Multiple comparison statistical results explaining the influence of walking and prosthesis stiffness conditions.

\begin{tabular}{|c|c|c|c|c|c|c|c|c|c|c|c|c|}
\hline \multirow{2}{*}{ Parameter } & \multicolumn{4}{|c|}{ Walking Scenario Effect } & \multicolumn{4}{|c|}{ Dorsiflexion Stiffness Effect } & \multicolumn{4}{|c|}{ Plantar Flexion Stiffness Effect } \\
\hline & Comp & $95 \%$ CI & $p$-Value & ES & Comp & 95\% CI & $p$-Value & ES & Comp & $95 \%$ CI & $p$-Value & ES \\
\hline Time to Foot- & DOWN > SSWS & $1.7(0.135,3.234)$ & 0.03 & 1.4 & - & - & - & - & $\mathrm{HI}>\mathrm{LO} 2$ & $.2(1.279,3.114)$ & 0.001 & 2.2 \\
\hline Flat $(\%$ & DOWN $>$ FWS & $1.8(0.293,3.392)$ & 0.01 & 1.5 & $\mathrm{HI}>\mathrm{LO}$ & - & - & - & - & - & - & - \\
\hline stance) & DOWN $>$ UP & $3.2(1.650,4.746)$ & 0.001 & 2.6 & - & - & - & - & - & - & - & - \\
\hline $\begin{array}{l}\text { Prosthetic Limb } \\
\text { Swing Time } \\
\text { CV }(\%)\end{array}$ & $\mathrm{UP}>\mathrm{FWS}$ & $1.0(0.200,1.800)$ & 0.01 & 1.5 & - & $0.6(0.1,1.0)$ & 0.009 & 1.3 & - & - & - & - \\
\hline Step Time CV & UP $>$ FWS & $2.0(0.200,3.800)$ & 0.03 & 1.5 & $\mathrm{HI}>\mathrm{LO}$ & $1.6(0.7,2.6)$ & 0.001 & 1.4 & - & - & - & - \\
\hline$(\%)$ & $\mathrm{UP}>\mathrm{DOWN}$ & $2.4(0.500,4.200)$ & 0.006 & 1.8 & & & & & & - & - & - \\
\hline $\begin{array}{l}\text { Step Width (\% } \\
\text { height) }\end{array}$ & - & - & - & - & $\mathrm{HI}>\mathrm{LO}$ & $0.6(0.205,0.932)$ & 0.003 & 1.4 & - & - & - & - \\
\hline $\begin{array}{l}\text { Symmetry } \\
\text { Ratio }\end{array}$ & FWS $>$ UP & $0.03(0.007,0.059)$ & 0.008 & 1.5 & $\mathrm{LO}>\mathrm{HI}$ & $0.03(0.013,0.041)$ & 0.001 & 1.9 & - & - & - & - \\
\hline
\end{tabular}

and plantar flexion stiffness at each walking condition are values resulting from collapsing across the remaining stiffness variable. For example, low dorsiflexion collapses values of LOLO and LOHI. Apart from the symmetry ratio, a decrease in each dependent variable would suggest an improvement in gait stability. For all dependent variables, the trends are consistent to suggest that low rotational stiffness improves gait stability. 


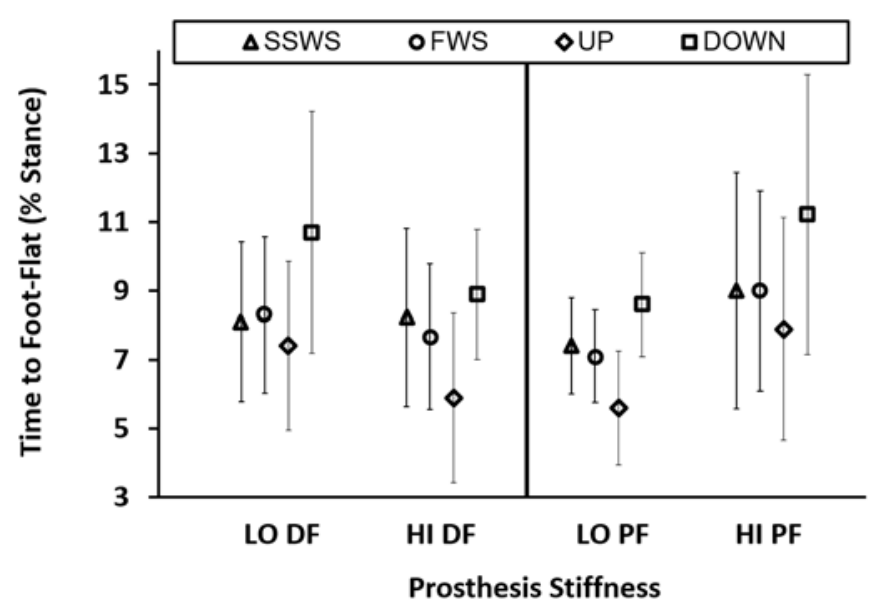

Figure 2.

Independent main effects of plantar flexion (PF) and dorsiflexion (DF) on time to foot-flat for each walking condition. Error bars are 95 percent confidence intervals. DOWN = selfselected walking speed on a 5 percent downhill slope, FWS = fast walking speed on the level, $\mathrm{HI}=$ high stiffness, $\mathrm{LO}=$ low stiffness, SSWS = self-selected walking speed on the level, UP = self-selected walking speed on a 5 percent uphill slope.

With all data grouped, level of perceived stability was moderately and negatively correlated with the time to prosthetic foot-flat $(p=0.008, \rho=-0.301)$.

\section{DISCUSSION}

This study aimed to explore the effects of prosthetic ankle rotational stiffness on gait stability of individuals with unilateral transtibial amputation.

\section{Effects of Rotational Stiffness on Time to Foot-Flat}

The hypothesis that LO plantar flexion would decrease the time to foot-flat was supported, and this result demonstrates that LO plantar flexion ankle components have the potential to generate a stable base of support in early stance. Across all walking conditions, the low plantar flexion stiffness condition (LOLO and HILO) decreased the time to foot-flat by 2.2 percent of stance (Table 3), and, as expected, this feature was not affected by dorsiflexion stiffness. This change represents a 26 percent reduction relative to the time to foot-flat of the HI plantar flexion and was sufficient to possess a moderate strength and negative correlation with user-

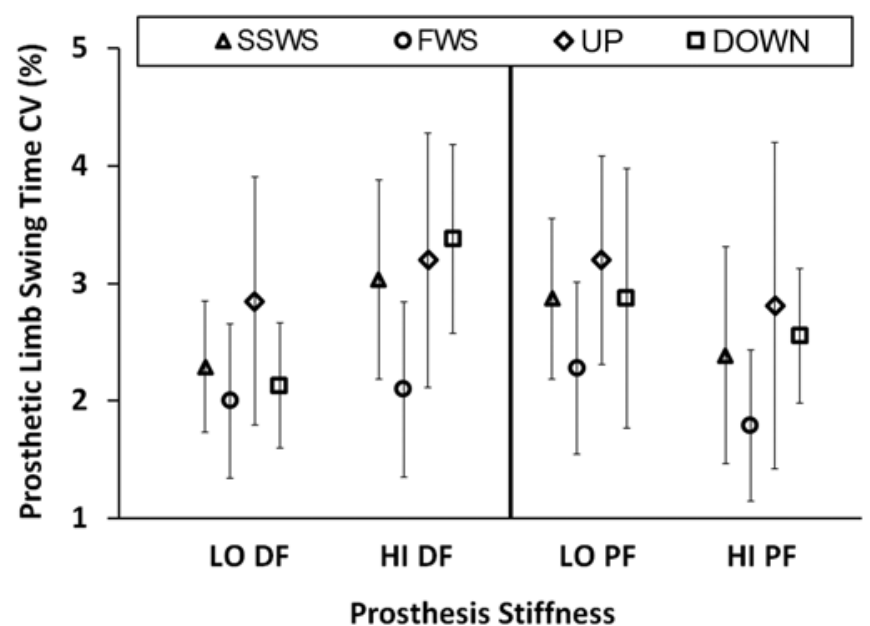

Figure 3.

Independent main effects of plantar flexion (PF) and dorsiflexion (DF) on prosthetic limb swing time coefficient of variation (CV) for each walking condition. Error bars are 95 percent confidence intervals. DOWN = self-selected walking speed on a 5 percent downhill slope, FWS $=$ fast walking speed on the level, $\mathrm{HI}=$ high stiffness, $\mathrm{LO}=$ low stiffness, SSWS = selfselected walking speed on the level, UP = self-selected walking speed on a 5 percent uphill slope.

perceived level of stability, thereby further supporting the hypothesis that user perception of increased stability is associated with experiencing early foot-flat.

Perceived level of stability and balance confidence is an important psychological component to a user's quality of life, since increased confidence can encourage engagement in daily activity and accelerate rehabilitation progress when properly addressed [2,47,51-52]. Consequently, clinicians may be able to take advantage of prosthetic designs that facilitate early foot-flat to address user concerns with stability during ambulation.

\section{Effects of Rotational Stiffness on Step Width}

The results suggest that HI dorsiflexion, which generates sagittal-plane joint-level kinematics that reflect unstable postures (e.g., restricted tibial progression on the prosthetic-side and a more extended sound knee during midstance) [36], was associated with increased step width and hence increased medial-lateral base of support. The mean increase in step width was 0.6 percent of height, which was similar in magnitude to the 1.0 percent of height increase observed in people with bilateral 


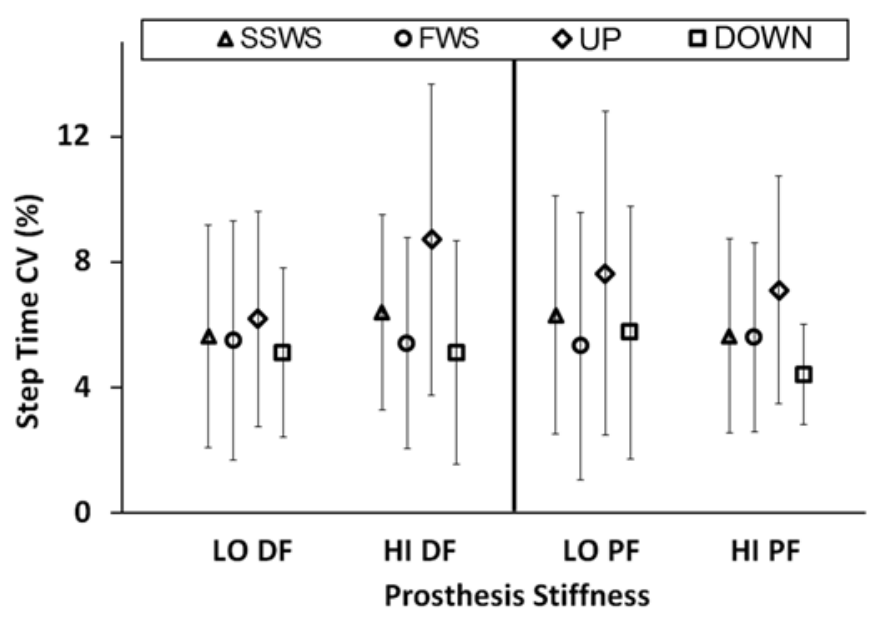

Figure 4.

Independent main effects of plantar flexion (PF) and dorsiflexion (DF) on step time coefficient of variation (CV) for each walking condition. Error bars are 95 percent confidence intervals. DOWN = self-selected walking speed on a 5 percent downhill slope, FWS = fast walking speed on the level, $\mathrm{HI}=$ high stiffness, LO = low stiffness, SSWS = self-selected walking speed on the level, UP = self-selected walking speed on a 5 percent uphill slope.

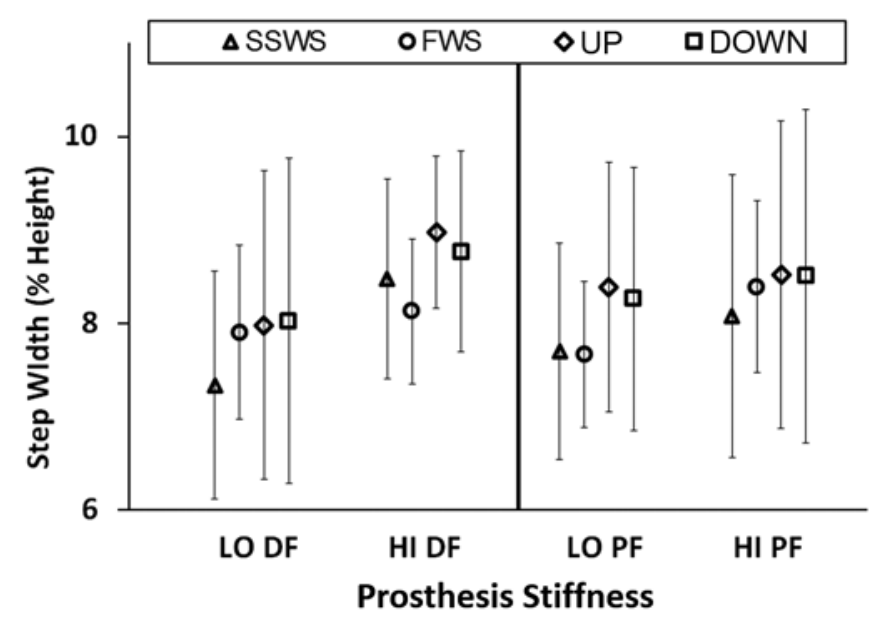

Figure 5.

Independent main effects of plantar flexion (PF) and dorsiflexion (DF) on step width for each walking condition. Error bars are 95 percent confidence intervals. DOWN = self-selected walking speed on a 5 percent downhill slope, FWS = fast walking speed on the level, $\mathrm{HI}=$ high stiffness, LO = low stiffness, SSWS = self-selected walking speed on the level, UP = selfselected walking speed on a 5 percent uphill slope.

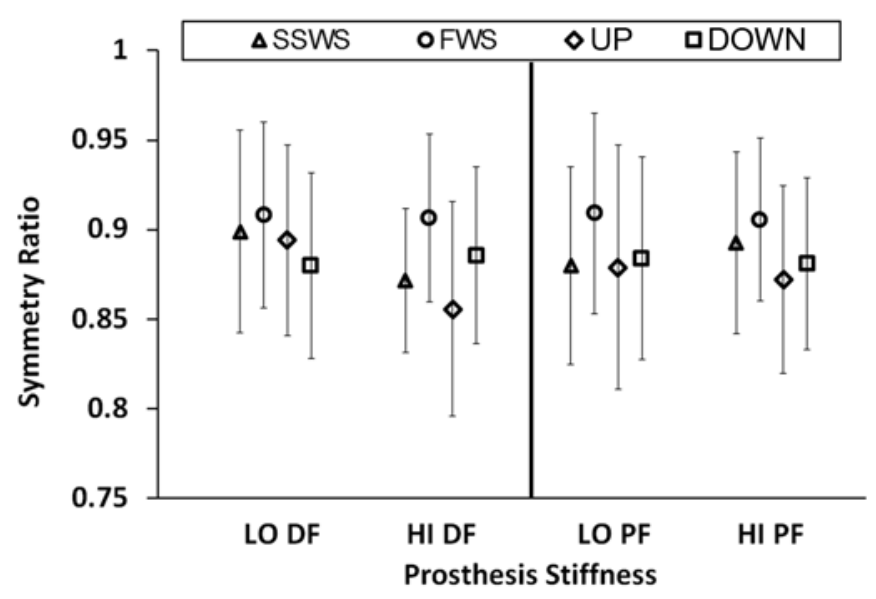

Figure 6.

Independent main effects of plantar flexion (PF) and dorsiflexion (DF) on symmetry for each walking condition. Error bars are 95 percent confidence intervals. DOWN = self-selected walking speed on a 5 percent downhill slope, FWS = fast walking speed on the level, $\mathrm{HI}=$ high stiffness, $\mathrm{LO}=$ low stiffness, SSWS = self-selected walking speed on the level, UP = self-selected walking speed on a 5 percent uphill slope.

amputation when using prostheses of decreased range of motion [13], thereby suggesting that this difference potentially holds clinical relevance. Relative to the step width for the LO dorsiflexion, this change represents a 68 percent increase. These relationships cannot explain a causal relationship, however; further research is warranted to identify whether improved perceptions of stability encourage a reduction in step width when independent of changes in prosthesis stiffness. Additionally, although reductions in step width may suggest improved perceived stability, this gait adjustment may also present additional stability risks because this further reduces the medial-lateral base of support [13], which should also be considered when prescribing components to address perception of stability.

\section{Effects of Rotational Stiffness on Temporal Variability and Symmetry}

The overall results strongly suggest support for the hypothesis that LO dorsiflexion facilitates improved gait stability. The significant pairwise comparisons for prosthetic limb swing time $\mathrm{CV}$, step time $\mathrm{CV}$, and symmetry all indicated that LO dorsiflexion results in changes that suggest improved walking stability and reduced fall risk, and none 
of these outcomes were affected by plantar flexion stiffness. Confidence that this trend is meaningful is supported by the fact that all three of these outcome metrics are considered proxy measures of gait stability and each was affected in the same direction by the main effect of dorsiflexion stiffness.

Across all walking conditions, the mean difference in prosthetic limb swing time $\mathrm{CV}$ and bilateral step time $\mathrm{CV}$ was 0.6 percent and 1.6 percent, respectively (Table 3 ), which, although small, are similar in magnitude to the difference observed in previous research between unilateral transtibial amputee fallers and nonfallers (1.4\%) [53]. Consequently, because some limited evidence suggests that this change in temporal variability is clinically relevant and that even slight increases may indicate increased fall risk in this population, use of LO dorsiflexion may be a reasonable clinical prescription objective to enhance gait stability. Furthermore, across all walking conditions, the mean increase in temporal symmetry for LO dorsiflexion was 0.03. Although this trend suggests improved symmetry during gait, this value is considerably smaller than the maximum differences observed in people with unilateral transtibial amputation when walking with varying prosthetic feet $(0.16)$, and as such the clinical relevance of this change is unknown [26].

The improvements in temporal variability and symmetry associated with LO dorsiflexion are likely related to the positive effects of LO dorsiflexion on joint-level kinematics that approach those of nondisabled, nonamputee gait [36]. LO dorsiflexion provides increased dorsiflexion motion and more natural tibial progression that seems to promote gait symmetry by not encouraging sound side compensations. There is some evidence that low prosthetic stiffness facilitates amputated-side limb muscle activation patterns that may enhance stability during stance [37], but the underlying motor control adaptations that are responsible for the observed reductions in temporal variability in this study are not fully understood and certainly warrant future work.

Because improved temporal variability and symmetry have been associated with reductions in fall risk and gait unsteadiness [14,16-21,25,38], and improved balance confidence benefits lower-limb prosthesis users' quality of life, these results suggest that, independent of alignment, selection of prosthetic feet that offer low rotational resistance and increased range of motion could benefit rehabilitation outcomes of patients at risk of unsteadiness and falls [2,47,51-52]. Although the changes in temporal variability and symmetry are small between high and low rotational stiffness, the trends appear to be meaningful and worth investigating further to determine their true clinical relevance. Irrespective of alignment, these results suggest that prosthesis stiffness could be a direct modifiable factor to be considered for prescription guidelines to influence a user's perceived stability and fall risk. The common standard of practice in rehabilitation for people with amputation is to optimally match patients with prosthetic components to maximize mobility outcomes, so the outcomes from this study provide valuable insight into our understanding of prostheses effects on user performance [40]. The prescription process will be further enhanced as techniques are improved for classifying patients based on their rehabilitation potential and mobility and classifying prostheses based on their amputee-independent mechanical properties [41,54-56].

\section{Effects of Walking Scenario on Temporal Variability and Symmetry}

The results from the main effect differences in walking condition appear to suggest that the incline walking condition presented the most challenging walking scenario across prosthesis conditions, as reflected by increased temporal variability and asymmetry. The mean differences in prosthetic swing time $\mathrm{CV}$, step time $\mathrm{CV}$, and symmetry ratio for those significant pairwise comparisons were similar in magnitude to the dorsiflexion main effect differences, suggesting that the impairments imposed by incline walking may be equivalent to those experienced by increasing dorsiflexion stiffness. This result is not surprising because anecdotal clinical evidence suggests that when dorsiflexion is too high, patients report a feeling of walking uphill because tibial progression is restricted. Consequently, the challenge to achieve stability during incline walking and $\mathrm{HI}$ dorsiflexion may be similar, and these results would partially support this conclusion. Overall, these results suggest that, irrespective of the prosthesis mechanical function, incline walking in the community may exacerbate unsteadiness and fall risk, so use of prostheses with LO dorsiflexion may mitigate those effects.

\section{Study Limitations}

The statistical power of the preliminary study was likely limited by the small sample size, which was a result of the logistical and recruitment difficulties associated with studies of people with amputation as well as the 
costly and time-consuming process of manufacturing custom experimental prostheses for all participants instead of using participants' own commercial prostheses. However, the statistical analysis was selected to help address this limitation, and the results demonstrate significant main effect differences for all three independent variables, suggesting that the small sample size may not have been a considerable limitation. Effect sizes ranged from 1.3 to 2.6, which would be considered large effects [57]. However, future studies are encouraged to include more participants to improve confidence intervals and aid in generalizability of the results.

Several other limitations may compromise the clinical relevance of this study. First, because of the short accommodation time provided for each prosthesis setting, this study only observed acute effects on gait performance, and future studies should consider long-term community outcomes (e.g., fall incidence). Second, the tested stiffness settings and foot length were the same for each participant and not body mass and height specific, respectively, which does not agree with common clinical practice of assigning foot stiffness and length based on user mass, height, and activity level, and may therefore have introduced participant-specific compensatory mechanisms. However, we would expect similar within-subject trends with changes in rotational stiffness consistent with this study. Additionally, subjects did not report any discomfort during testing that would suggest that the use of generalized parameters influenced their performance beyond the tested effects. Third, only one alignment was used for each participant during testing, regardless of stiffness condition, which again is contradictory to standard clinical practice of aligning prostheses. However, the aim of this study was to investigate isolated effects of plantar flexion and dorsiflexion stiffness on gait stability, so it was important to observe these effects independent of alignment. Realigning the prosthesis each time the CFAM stiffness was adjusted would have introduced additional independent variables, confounding our results and preventing exploration of how changes in ankle stiffness alone could be used by clinicians and prosthesis designers to influence gait quality and user-perceived stability. In reality, both alignment and user-independent prosthesis mechanical function interact to affect gait stability, and these interactions form a basis for future work. It is important to note that the results are interpreted based on literature suggesting a positive linear relationship between temporal variability and falls. Future research is warranted to identify whether instead a Ushape relationship applies to lower-limb prosthesis users, as evidence has suggested for elderly individuals and step width variability [58].

\section{CONCLUSIONS}

This is the first study to report on the effects that systematic changes in prosthetic ankle stiffness have on gait parameters that are reflective of gait stability in people with transtibial amputation. This preliminary study supports the hypotheses that decreased plantar flexion and dorsiflexion stiffnesses are associated with enhanced user-perceived and actual gait stability, contributing to reduced fall risk and increased quality of life. Although the measured trends appear meaningful, future studies should consider additional values of rotational stiffness (i.e., with increased resolution and over a greater range) to more fully characterize changes in gait parameters as a function of prosthesis properties and explore the clinical relevance of these effects. Future work should also consider similar systematic investigations for additional mobility activities to study relationships between prosthesis properties and user stability across a greater range of daily living activity. Generally, the trends in this study suggest that clinicians can improve prosthesis prescription to maximize gait stability by recommending prosthetic foot-ankle mechanisms with low rotational stiffness, and this could be considered independent of changes in alignment. Ultimately, the clinical method of designing low rotational stiffness prostheses would be dependent on the componentry as chosen based on various clinical and subject-specific factors, and may reasonably include selection of deformable elastomers for articulated devices and continuous elements (e.g., leaf springs) for nonarticulated devices.

\section{ACKNOWLEDGMENTS}

\section{Author Contributions:}

Study concept and design: M. J. Major, M. Twiste, L. P. J. Kenney, D. Howard.

Acquisition of data: M. J. Major.

Analysis and interpretation of data: M. J. Major, M. Twiste,

L. P. J. Kenney, D. Howard.

Drafting of manuscript: M. J. Major, M. Twiste, L. P. J. Kenney, D. Howard. 
Critical revision of manuscript for important intellectual content:

M. J. Major, M. Twiste, L. P. J. Kenney, D. Howard.

Statistical analysis: M. J. Major.

Obtained funding: M. J. Major.

Administrative, technical, or material support: M. J. Major, M. Twiste.

Study supervision: M. Twiste, L. P. J. Kenney, D. Howard.

Financial Disclosures: The authors have declared that no competing interests exist.

Funding/Support: This material was based on work supported in part by the Department of Veterans Affairs, Veterans Health Administration, Rehabilitation Research and Development Service (award 1IK2RX001322-01A1).

Additional Contributions: The authors wish to thank Colin Smith for his assistance in fabrication of components for the experimental prosthesis and Ruth Nicholson for her assistance in fabrication of the test sockets.

Institutional Review: Ethical approval was obtained from the local National Health Service and Salford University institutional review boards.

Participant Follow-Up: The authors have no plans to notify the study subjects of the publication of this article because of a lack of current contact information.

\section{REFERENCES}

1. Miller WC, Speechley M, Deathe B. The prevalence and risk factors of falling and fear of falling among lower extremity amputees. Arch Phys Med Rehabil. 2001;82(8): 1031-7. [PMID:11494181] http://dx.doi.org/10.1053/apmr.2001.24295

2. Miller WC, Speechley M, Deathe AB. Balance confidence among people with lower-limb amputations. Phys Ther. 2002;82(9):856-65. [PMID:12201800]

3. Miller WC, Deathe AB, Speechley M, Koval J. The influence of falling, fear of falling, and balance confidence on prosthetic mobility and social activity among individuals with a lower extremity amputation. Arch Phys Med Rehabil. 2001;82(9):1238-44. [PMID:11552197] http://dx.doi.org/10.1053/apmr.2001.25079

4. Quai TM, Brauer SG, Nitz JC. Somatosensation, circulation and stance balance in elderly dysvascular transtibial amputees. Clin Rehabil. 2005;19(6):668-76. [PMID:16180604] http://dx.doi.org/10.1191/0269215505cr857oa

5. van Velzen JM, van Bennekom CA, Polomski W, Slootman JR, van der Woude LH, Houdijk H. Physical capacity and walking ability after lower limb amputation: A systematic review. Clin Rehabil. 2006;20(11):999-1016.

[PMID:17065543] http://dx.doi.org/10.1177/0269215506070700

6. Kavounoudias A, Tremblay C, Gravel D, Iancu A, Forget R. Bilateral changes in somatosensory sensibility after uni- lateral below-knee amputation. Arch Phys Med Rehabil. 2005;86(4):633-40. [PMID:15827911] http://dx.doi.org/10.1016/j.apmr.2004.10.030

7. Geurts AC, Mulder TW, Nienhuis B, Rijken RA. Postural reorganization following lower limb amputation: Possible motor and sensory determinants of recovery. Scand J Rehabil Med. 1992;24(2):83-90. [PMID:1604266]

8. Pedrinelli A, Saito M, Coelho RF, Fontes RB, Guarniero R. Comparative study of the strength of the flexor and extensor muscles of the knee through isokinetic evaluation in normal subjects and patients subjected to transtibial amputation. Prosthet Orthot Int. 2002;26(3):195-205.

[PMID:12562066]

http://dx.doi.org/10.1080/03093640208726648

9. Nadollek H, Brauer S, Isles R. Outcomes after transtibial amputation: The relationship between quiet stance ability, strength of hip abductor muscles and gait. Physiother Res Int. 2002;7(4):203-14. [PMID:12528576]

http://dx.doi.org/10.1002/pri.260

10. Hof AL, van Bockel RM, Schoppen T, Postema K. Control of lateral balance in walking: Experimental findings in normal subjects and above-knee amputees. Gait Posture. 2007; 25(2):250-8. [PMID:16740390] http://dx.doi.org/10.1016/j.gaitpost.2006.04.013

11. Vanicek N, Strike S, McNaughton L, Polman R. Postural responses to dynamic perturbations in amputee fallers versus nonfallers: A comparative study with able-bodied subjects. Arch Phys Med Rehabil. 2009;90(6):1018-25.

[PMID:19480879]

http://dx.doi.org/10.1016/j.apmr.2008.12.024

12. Nederhand MJ, Van Asseldonk EH, van der Kooij H, Rietman HS. Dynamic Balance Control (DBC) in lower leg amputee subjects: Contribution of the regulatory activity of the prosthesis side. Clin Biomech (Bristol, Avon). 2012; 27(1):40-5. [PMID:21889241] http://dx.doi.org/10.1016/j.clinbiomech.2011.07.008

13. Major MJ, Stine RL, Gard SA. The effects of walking speed and prosthetic ankle adapters on upper extremity dynamics and stability-related parameters in bilateral transtibial amputee gait. Gait Posture. 2013;38(4):858-63. [PMID:23680427] http://dx.doi.org/10.1016/j.gaitpost.2013.04.012

14. Hausdorff JM. Gait variability: Methods, modeling and meaning. J Neuroeng Rehabil. 2005;2:19. [PMID:16033650] http://dx.doi.org/10.1186/1743-0003-2-19

15. Bruijn SM, Meijer OG, Beek PJ, van Dieën JH. Assessing the stability of human locomotion: A review of current measures. J R Soc Interface. 2013;10(83):20120999. [PMID:23516062] http://dx.doi.org/10.1098/rsif.2012.0999 
16. Hausdorff JM, Edelberg HK, Mitchell SL, Goldberger AL, Wei JY. Increased gait unsteadiness in community-dwelling elderly fallers. Arch Phys Med Rehabil. 1997;78(3): 27883. [PMID:9084350] http://dx.doi.org/10.1016/S0003-9993(97)90034-4

17. Hausdorff JM, Rios DA, Edelberg HK. Gait variability and fall risk in community-living older adults: A 1-year prospective study. Arch Phys Med Rehabil. 2001;82(8):1050-6. [PMID:11494184] http://dx.doi.org/10.1053/apmr.2001.24893

18. Ring H, Treger I, Gruendlinger L, Hausdorff JM. Neuroprosthesis for footdrop compared with an ankle-foot orthosis: Effects on postural control during walking. J Stroke Cerebrovasc Dis. 2009;18(1):41-7. [PMID:19110144] http://dx.doi.org/10.1016/j.jstrokecerebrovasdis.2008.08.006

19. Vanicek N, Strike S, McNaughton L, Polman R. Gait patterns in transtibial amputee fallers vs. non-fallers: Biomechanical differences during level walking. Gait Posture. 2009;29(3):415-20. [PMID:19071021] http://dx.doi.org/10.1016/j.gaitpost.2008.10.062

20. Hausdorff JM, Cudkowicz ME, Firtion R, Wei JY, Goldberger AL. Gait variability and basal ganglia disorders: Stride-to-stride variations of gait cycle timing in Parkinson's disease and Huntington's disease. Mov Disord. 1998; 13(3):428-37. [PMID:9613733] http://dx.doi.org/10.1002/mds.870130310

21. Maki BE. Gait changes in older adults: Predictors of falls or indicators of fear. J Am Geriatr Soc. 1997;45(3):313-20. [PMID:9063277] http://dx.doi.org/10.1111/j.1532-5415.1997.tb00946.x

22. Segal AD, Klute GK. Lower-limb amputee recovery response to an imposed error in mediolateral foot placement. J Biomech. 2014;47(12):2911-8. [PMID:25145315] http://dx.doi.org/10.1016/j.jbiomech.2014.07.008

23. Winter DA, Sienko SE. Biomechanics of below-knee amputee gait. J Biomech. 1988;21(5):361-7.

[PMID:3417688] http://dx.doi.org/10.1016/0021-9290(88)90142-X

24. Baker PA, Hewison SR. Gait recovery pattern of unilateral lower limb amputees during rehabilitation. Prosthet Orthot Int. 1990;14(2):80-4. [PMID:2235305]

25. Donker SF, Beek PJ. Interlimb coordination in prosthetic walking: Effects of asymmetry and walking velocity. Acta Psychol (Amst). 2002;110(2-3):265-88.

[PMID:12102109]

http://dx.doi.org/10.1016/S0001-6918(02)00037-9

26. Marinakis GN. Interlimb symmetry of traumatic unilateral transtibial amputees wearing two different prosthetic feet in the early rehabilitation stage. J Rehabil Res Dev. 2004; 41(4):581-90. [PMID:15558386] http://dx.doi.org/10.1682/JRRD.2003.04.0049
27. Schmid M, Beltrami G, Zambarbieri D, Verni G. Centre of pressure displacements in trans-femoral amputees during gait. Gait Posture. 2005;21(3):255-62. [PMID:15760740] http://dx.doi.org/10.1016/j.gaitpost.2004.01.016

28. Nolan L, Wit A, Dudziñski K, Lees A, Lake M, Wychowañski M. Adjustments in gait symmetry with walking speed in trans-femoral and trans-tibial amputees. Gait Posture. 2003;17(2):142-51. [PMID:12633775] http://dx.doi.org/10.1016/S0966-6362(02)00066-8

29. Lemaire ED, Fisher FR. Osteoarthritis and elderly amputee gait. Arch Phys Med Rehabil. 1994;75(10):1094-9. [PMID:7944914] http://dx.doi.org/10.1016/0003-9993(94)90084-1

30. Lehmann JF, Price R, Boswell-Bessette S, Dralle A, Questad K, deLateur BJ. Comprehensive analysis of energy storing prosthetic feet: Flex Foot and Seattle Foot versus standard SACH foot. Arch Phys Med Rehabil. 1993; 74(11):1225-31. [PMID:8239969]

31. Yogev G, Plotnik M, Peretz C, Giladi N, Hausdorff JM. Gait asymmetry in patients with Parkinson's disease and elderly fallers: When does the bilateral coordination of gait require attention? Exp Brain Res. 2007;177(3):336-46. [PMID:16972073] http://dx.doi.org/10.1007/s00221-006-0676-3

32. Perry J, Boyd LA, Rao SS, Mulroy SJ. Prosthetic weight acceptance mechanics in transtibial amputees wearing the Single Axis, Seattle Lite, and Flex Foot. IEEE Trans Rehabil Eng. 1997;5(4):283-9. [PMID:9422453] http://dx.doi.org/10.1109/86.650279

33. Goh JC, Solomonidis SE, Spence WD, Paul JP. Biomechanical evaluation of SACH and uniaxial feet. Prosthet Orthot Int. 1984;8(3):147-54. [PMID:6522257]

34. Torburn L, Schweiger GP, Perry J, Powers CM. Below-knee amputee gait in stair ambulation: A comparison of stride characteristics using five different prosthetic feet. Clin Orthop Relat Res. 1994;(303):185-92. [PMID:8194232]

35. Rao SS, Boyd LA, Mulroy SJ, Bontrager EL, Gronley JK, Perry J. Segment velocities in normal and transtibial amputees: Prosthetic design implications. IEEE Trans Rehabil Eng. 1998;6(2):219-26. [PMID:9631330] http://dx.doi.org/10.1109/86.681188

36. Major MJ, Twiste M, Kenney LP, Howard D. The effects of prosthetic ankle stiffness on ankle and knee kinematics, prosthetic limb loading, and net metabolic cost of transtibial amputee gait. Clin Biomech (Bristol, Avon). 2014; 29(1):98-104. [PMID:24238976]

http://dx.doi.org/10.1016/j.clinbiomech.2013.10.012

37. Fey NP, Klute GK, Neptune RR. The influence of energy storage and return foot stiffness on walking mechanics and muscle activity in below-knee amputees. Clin Biomech (Bristol, Avon). 2011;26(10):1025-32. [PMID:21777999] http://dx.doi.org/10.1016/j.clinbiomech.2011.06.007 
38. Su PF, Gard SA, Lipschutz RD, Kuiken TA. The effects of increased prosthetic ankle motions on the gait of persons with bilateral transtibial amputations. Am J Phys Med Rehabil. 2010;89(1):34-47. [PMID:20026945] http://dx.doi.org/10.1097/PHM.0b013e3181c55ad4

39. Vrieling AH, van Keeken HG, Schoppen T, Otten E, Halbertsma JP, Hof AL, Postema K. Uphill and downhill walking in unilateral lower limb amputees. Gait Posture. 2008; 28(2):235-42. [PMID:18242995] http://dx.doi.org/10.1016/j.gaitpost.2007.12.006

40. Major MJ, Kenney LP, Twiste M, Howard D. Stance phase mechanical characterization of transtibial prostheses distal to the socket: A review. J Rehabil Res Dev. 2012;49(6): 815-29. [PMID:23299254] http://dx.doi.org/10.1682/JRRD.2011.06.0108

41. Major MJ, Twiste M, Kenney LP, Howard D. Amputee independent prosthesis properties: A new model for description and measurement. J Biomech. 2011;44(14): 2572-5. [PMID:21831379]

http://dx.doi.org/10.1016/j.jbiomech.2011.07.016

42. Major MJ. The influence of the mechanical properties of transtibial prostheses on amputee performance [dissertation]. Salford (UK): University of Salford; 2010.

43. Zahedi MS, Spence WD, Solomonidis SE, Paul JP. Alignment of lower-limb prostheses. J Rehabil Res Dev. 1986; 23(2):2-19. [PMID:3723422]

44. Zeni JA Jr, Higginson JS. Gait parameters and stride-tostride variability during familiarization to walking on a split-belt treadmill. Clin Biomech (Bristol, Avon). 2010; 25(4):383-6. [PMID:20004501] http://dx.doi.org/10.1016/j.clinbiomech.2009.11.002

45. Brach JS, Perera S, Studenski S, Newman AB. The reliability and validity of measures of gait variability in community-dwelling older adults. Arch Phys Med Rehabil. 2008; 89(12):2293-6. [PMID:19061741] http://dx.doi.org/10.1016/j.apmr.2008.06.010

46. Powell LE, Myers AM. The Activities-specific Balance Confidence (ABC) Scale. J Gerontol A Biol Sci Med Sci. 1995;50A(1):M28-M34. [PMID:7814786] http://dx.doi.org/10.1093/gerona/50A.1.M28

47. Miller WC, Deathe AB, Speechley M. Psychometric properties of the Activities-specific Balance Confidence Scale among individuals with a lower-limb amputation. Arch Phys Med Rehabil. 2003;84(5):656-61. [PMID:12736877] http://dx.doi.org/10.1016/S0003-9993(02)04807-4

48. Major MJ, Fatone S, Roth EJ. Validity and reliability of the Berg Balance Scale for community-dwelling persons with lower-limb amputation. Arch Phys Med Rehabil. 2013; 94(11):2194-202. [PMID:23856150] http://dx.doi.org/10.1016/j.apmr.2013.07.002

49. O’Connor CM, Thorpe SK, O’Malley MJ, Vaughan CL. Automatic detection of gait events using kinematic data.
Gait Posture. 2007;25(3):469-74. [PMID:16876414]

http://dx.doi.org/10.1016/j.gaitpost.2006.05.016

50. Cappozzo A, Catani F, Croce UD, Leardini A. Position and orientation in space of bones during movement: Anatomical frame definition and determination. Clin Biomech (Bristol, Avon). 1995;10(4):171-8. [PMID:11415549] http://dx.doi.org/10.1016/0268-0033(95)91394-T

51. Asano M, Rushton P, Miller WC, Deathe BA. Predictors of quality of life among individuals who have a lower limb amputation. Prosthet Orthot Int. 2008;32(2):231-43. [PMID: 18569891] http://dx.doi.org/10.1080/03093640802024955

52. Miller WC, Deathe AB. A prospective study examining balance confidence among individuals with lower limb amputation. Disabil Rehabil. 2004;26(14-15):875-81. [PMID:15497916] http://dx.doi.org/10.1080/09638280410001708887

53. Parker K, Hanada E, Adderson J. Gait variability and regularity of people with transtibial amputations. Gait Posture. 2013;37(2):269-73. [PMID:22939409] http://dx.doi.org/10.1016/j.gaitpost.2012.07.029

54. Gailey RS, Roach KE, Applegate EB, Cho B, Cunniffe B, Licht S, Maguire M, Nash MS. The amputee mobility predictor: An instrument to assess determinants of the lowerlimb amputee's ability to ambulate. Arch Phys Med Rehabil. 2002;83(5):613-27. [PMID:11994800] http://dx.doi.org/10.1053/apmr.2002.32309

55. Kaluf B. Evaluation of mobility in persons with limb loss using the Amputee Mobility Predictor and the Prosthesis Evaluation Questionnaire-Mobility Subscale: A six-month retrospective chart review. J Prosthet Orthot. 2014;26(2): 70-6. http://dx.doi.org/10.1097/JPO.0000000000000020

56. Major MJ, Johnson WB, Gard SA. Interrater reliability of mechanical tests for functional classification of transtibial prosthesis components distal to the socket. J Rehabil Res Dev. 2015;52(4):467-76. [PMID:26360815] http://dx.doi.org/10.1682/JRRD.2014.12.0300

57. Cohen J. Statistical power analysis for the behavioral sciences. 2nd ed. Hillsdale (NJ): Lawrence Erlbaum Associates, Inc.; 1988.

58. Brach JS, Berlin JE, VanSwearingen JM, Newman AB, Studenski SA. Too much or too little step width variability is associated with a fall history in older persons who walk at or near normal gait speed. J Neuroeng Rehabil. 2005; 2:21. [PMID:16042812] http://dx.doi.org/10.1186/1743-0003-2-21

Submitted for publication August 3, 2015. Accepted in revised form November 30, 2015.

This article and any supplementary material should be cited as follows: 
JRRD, Volume 53, Number 6, 2016

Major MJ, Twiste M, Kenney LPJ, Howard D. The effects of prosthetic ankle stiffness on stability of gait in people with transtibial amputation. J Rehabil Res Dev. 2016;53(6):839-52.

http://dx.doi.org/10.1682/JRRD.2015.08.0148
ORCID: Matthew J. Major, PhD: 0000-0002-2330-4619; Laurence P. J. Kenney, PhD: 0000-0003-2164-3892; Martin Twiste, PhD: 0000-0003-2724-3283

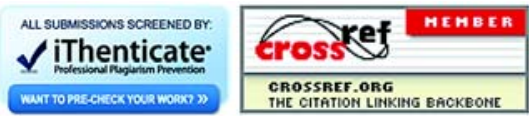

